\title{
"SE NECESITA UNA ALDEA PARA CRIAR A UN NIÑO..."
}

\section{"IT TAKES A VILLAGE TO RAISE A CHILD..."}

\author{
Sánchez Davila, Constanza \\ Odontóloga Especialista en Odontopediatría. Universidad San Francisco de Quito, Ecuador. \\ constanza120@hotmail.com
}

\begin{abstract}
Resumen
El presente artículo de opinión desarrolla el punto de vista de la autora respecto a la necesidad de entender el desarrollo del niño con una visión integral , así también la importancia de prevenir las enfermedades de los niños y tratar de mantenerlos sanos para una mejor vida adulta. La interacción entre profesionales cuando intervienen de manera conjunta implica considerar el efecto que tiene el trabajo de un profesional en los resultados del otro. En el desempeño profesional se ha evidenciado una posible relación existe entre la salud bucal y los logros académicos. Finalmente se invita a motivar a sugerir a los pacientes a cambiar sus hábitos de consumo de azúcar.
\end{abstract}

Palabras clave: Grupo de Atención al Paciente, Odontología Pediátrica, Desarrollo Infantil .

\begin{abstract}
This article of opinion develops the author's point of view regarding the need to understand the development of the child with a comprehensive vision, as well as the importance of preventing children's illnesses and trying to keep them healthy for a better adult life. The interaction between professionals when they intervene jointly involves considering the effect that the work of one professional has on the results of the other. In professional performance, a possible relationship exists between oral health and academic achievements. Finally, we encourage motivation to suggest to patients to change their sugar consumption habits.
\end{abstract}

Key words: Patient Care Team, Pediatric Dentistry, Child Development.

En el cuerpo humano existe un vínculo entre lo que sucede en la boca y lo que pasa en el corazón; de igual manera, en la comunidad médica pediátrica, hay una conexión entre lo que recomienda el médico y lo que sugiere el terapista del lenguaje, por ejemplo. "Se necesita una aldea, para criar a un niño" reza un proverbio africano que en las últimas décadas se ha escuchado mucho y que no podría ser más acertado. Esto quiere decir que un niño depende de su comunidad para desarrollarse como un ser humano pleno, sano y feliz. Y en esa comunidad estamos nosotros, los Odontopediatras. Somos varios los especialistas que tenemos en nuestras manos el desarrollo integral de nuestros pequeños pacientes. Los profesionales de la salud debemos ser multiplicadores de sabiduría y fomentar una cultura de salud y equilibrio. ¡Es importante que lo hagamos juntos! No olvidemos que un niño sano es un adulto sano. $\mathrm{Y}$ no solo eso: adultos sanos crean sociedades sanas.

A lo largo de los 18 años que he tenido el privilegio de trabajar como odontopediatra, he podido ser parte de las historias de las familias que pasan por mi consulta. No es solamente un niño el que está recostado en la silla. Son sus padres, sus hermanos, sus compañeros de colegio, sus maes- tros, sus amigos y, sí, también los especialistas que tenemos a nuestro cargo su salud. Nuestro rol en su crecimiento es muy importante. Tenemos la oportunidad de cambiar el rumbo de nuestra niñez y esa posibilidad se vuelve un compromiso moral.

No hacemos un trabajo: vivimos una vocación. En este contexto, es indispensable que tengamos plena conciencia del alcance de nuestra labor. Estamos en el Siglo XXI y, sin embargo, todavía vemos cómo los pequeños de nuestros países siguen padeciendo caries y asumiendo las duras consecuencias de este problema. Es de suma importancia recordar constantemente que nuestra principal prioridad es nuestro paciente. Nuestro más alto objetivo es su correcto desarrollo y a largo plazo la real evolución, no solo de ese niño, sino de su entorno, de su ciudad, de su país.

La excelencia no es una meta: Es un camino que nunca termina, y que nos exige seguir cumpliendo retos. ¿Y qué implica orientarse hacia la excelencia? Trabajar en un conjunto. No es fácil criar a un pequeño y hacerlo bien; por eso debemos fortalecernos como comunidad, dialogar, encontrarnos, compartir nuestros conocimientos y puntos de vista, respetar la perspectiva del otro y unificar criterios, para trabajar de ma- 
nera multidisciplinaria y alcanzar los resultados deseados. Es importante detenernos a pensar: ¿Cómo afecta mi trabajo al trabajo de mi colega? ¿Y cómo afecta mi trabajo al desarrollo integral del niño?

Como odontopediatra, me enfrento constantemente a la necesidad de compartir mis perspectivas con pediatras, psicólogos, enfermeras, terapistas del lenguaje, e incluso ginecólogos, pues desde que el bebé está en el vientre de una madre tenemos que propiciar el desarrollo adecuado de su salud oral. ¿Cómo? Si una madre tiene un paladar menos dulce y consume alimentos saludables, el bebé también. Todo se transmite a través de la madre. Así el bebé se acostumbra a crecer con un paladar más sano. De igual manera, si un pediatra se enfoca únicamente en su contexto médico, sin incluir el punto de vista odontológico, ignoraría, por ejemplo, que el niño debe tomar biberón solo hasta que cumpla un año, pues la mezcla del biberón con los alimentos a la hora de dormir es lo que destruye totalmente el esmalte de los dientes. Otro error común es descuidar los dientes de leche, ya que "de todas formas, esos dientes se van a caer". Pero todo tiene una función. Si el niño pierde sus dientes de una manera precoz, esto va a traer muchos problemas: malos hábitos, degluciones atípicas, mordidas abiertas, maloclusiones clase III, etc. Algunos se preguntarán. ¿Pero no estará exagerando? La respuesta es un contundente NO. Lo he visto en mi consulta. Pregunta cuál es el niño más inteligente de la clase y simplemente ábrele la boca. Él no tiene caries. Y si vemos que el niño que no rinde, nuevamente, ábrele la boca y revísala. Tiene la boca llena de caries; pero no puede manifestar su dolor, pues no sabe todavía qué es dolor. De allí que reaccione con irritabilidad, llanto, rebeldía, bajo rendimiento, falta de sueño y falta de apetito, entre otras cosas. Por supuesto, no podemos generalizar. Sin embargo, estas coincidencias son demasiado frecuentes como para seguir pasándolas por alto. De igual manera, si un niño tiene buena salud oral y es sometido a algún proceso quirúrgico, va a evolucionar correctamente. Pero si ese niño tiene la boca en mal estado y no se eliminan primero los focos de infección dentro de ésta, la recuperación de ese niño no será la más adecuada; más aún si se trata de transplante de órganos, en cuyo caso el paciente tiene muy altas probabilidades de rechazar el órgano. Y en el caso de que el niño sea un paciente cardíaco, puede llegar a desarrollar una endocarditis bacteriana, que podría llevarlo a la muerte.

Hablo, claro está, desde mi especialidad. Pero lo mismo sucederá desde otros puntos de vista. He sido testigo, por mencionar algunos casos de situaciones en las que la salud oral deficiente de un niño afecta la apariencia de sus pequeños dientes y lesiona sus relaciones interpersonales, o de adolescentes que se rehúsan a usar ortodoncia porque no quieren que altere la forma en que se ven. En ese caso es importante referirlos a una psicóloga, o dialogar con ella, para buscar formas de conducir estos casos de manera correcta, casos en los que la autoestima del niño también está en juego. Otro punto vital es que, además de dialogar entre todos los especialistas, debemos atrevernos a ir más allá. Tomar conciencia de nuestra responsabilidad y nuestro poder y tomarnos el tiempo para hablar con los padres, para educar, para insistir, aún hasta el cansancio y aún a pesar de cualquier resistencia que podamos encontrar en el camino. Es nuestro deber inculcar alimentación adecuada, hábitos saludables y la reducción de ingesta de azúcar que, a estas alturas, sabemos que afecta al niño en todos sus aspectos. No es solo un tema de caries, sino de malnutrición y mal desarrollo cognitivo. Hay mucho por hacer y no podemos desmayar. Es conveniente aprovechar festividades como las que acaban de pasar, como una excelente oportunidad para sugerir a nuestros pacientes cambiar las toneladas de azúcar por juguetes y regalos más positivos: cuadernos para pintar, juguetes didácticos, actividades divertidas, etc. Hay que motivarlos para mantener su mente ocupada en cosas que les permitan enriquecer su mente. Empecemos a ser agentes de cambio; tenemos todas las herramientas para lograrlo, el espíritu, la motivación y el talento para hacerlo!
Recibido: 28 de septiembre de 2018

Aceptado: 20 de octubre de 2018 